\title{
A constituição do ensino de leitura em objeto de pesquisas acadêmicas no Brasil
}

The constitution of teaching reading as an object of academic research in Brazil

La constitución de la enseñanza de la lectura como objeto de investigación académica en Brasil

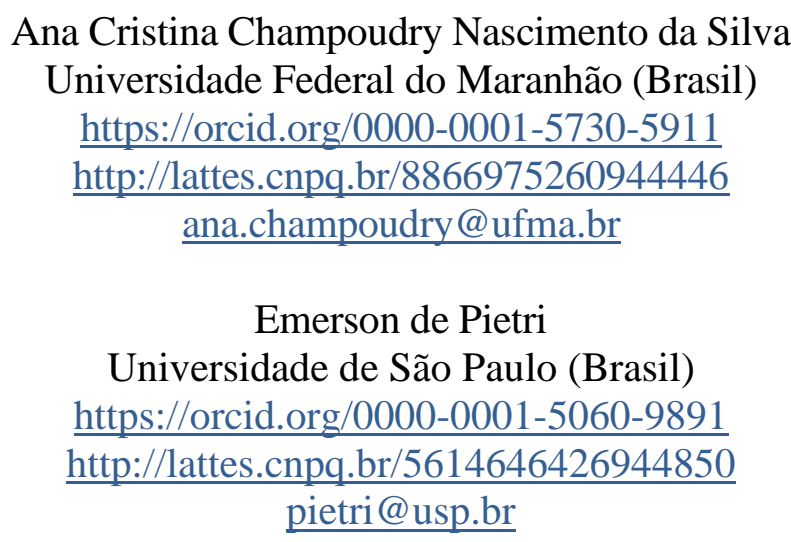

\section{Resumo}

Neste artigo são apresentados resultados de pesquisa orientada pelo objetivo de compreender os processos interdiscursivos que fundamentaram a formação de temas, bases conceituais e estratégias argumentativas para a constituição do ensino da leitura na escola básica em objeto de investigações científicas. Foram analisadas dissertações de mestrado desenvolvidas na década de 80 do século XX, em programas de pós-graduação no país. Os resultados mostram que a identificação da existência de uma crise da leitura referenciou a proposição de mudanças necessárias na educação leitora no ensino básico, para o que as pesquisas contribuiriam com a produção de subsídios teórico-metodológicos que transformassem as práticas pedagógicas e garantissem a formação emancipatória de leitores críticos.

Palavras-chave: Leitura. Pesquisa. Ensino. 


\begin{abstract}
In this article, results of research guided by the objective of understanding the interdiscursive processes that founded the constitution of reading as an object of scientific investigations are presented. Master's theses developed in graduate programs in Brazil in the 1980s of the 20th century were analyzed and the formation of themes, conceptual bases and argumentative strategies were characterized. The results show that the identification of a crisis in reading supported propositions on the necessary changes in reading education in basic school, for which academic investigations would contribute with the production of theoretical and methodological subsidies that could transform the pedagogical practices and guarantee the emancipatory teaching of critical readers.
\end{abstract}

Keywords: Reading. Scientific research. Portuguese language teaching.

\title{
Resumen
}

En este artículo se presentan resultados de investigaciones guiadas por el objetivo de comprender los procesos interdiscursivos que fundaron la constitución de la lectura como objeto de investigaciones científicas. Se analizaron las tesis de maestría desarrolladas en programas de posgrado en Brasil en la década de 1980 del siglo XX y se caracterizó la formación de temas, bases conceptuales y estrategias argumentativas. Los resultados muestran que la identificación de una crisis en la lectura fue la base para proponer cambios en la formación de lectores en la escuela básica, para los cuales las investigaciones académicas contribuirían con la producción de subsidios teóricos y metodológicos que podrían transformar las prácticas pedagógicas y garantizar la educación emancipadora de lectores críticos.

Palabras clave: Lectura. Investigación científica. Enseñanza de la lengua portuguesa. 


\section{Introdução}

Neste trabalho, apresentam-se resultados de pesquisa realizada com o objetivo de conhecer o modo como o ensino de leitura se constituiu em objeto de investigações acadêmicas no Brasil, nas décadas finais do século XX, período de ampliação do acesso à escolarização básica pública, quando o regime militar reposicionava a escola básica para que respondesse aos projetos de desenvolvimento econômico do país, e de reconfigurações curriculares, com seus efeitos para o ensino e aprendizagem e para a formação de professores (SILVA \& ARELARO, 1987).

A escola básica pública é considerada então como um espaço representativo da formação social brasileira, tanto por receber em seus bancos a heterogeneidade sócioeconômico-cultural da população que se movimentava do campo em direção às cidades naquele momento histórico (BEISIEGEL, 2013; FREITAS, 2014), quanto por possibilitar a formação de contingentes populacionais cada vez mais amplos para a apreensão crítica da realidade, de modo a produzirem-se instrumentos de luta política - dentre eles, os linguísticos - voltada à transformação da sociedade em direção a uma ordem social mais justa e igualitária (GERALDI, 1984; LUFT, 1985; SOARES, 1986).

No momento histórico em observação, implementaram-se, também, políticas públicas de ampliação e desenvolvimento de pesquisas em nível de pós-graduação no país. As primeiras experiências nesse nível de ensino se realizaram nos anos de 1930, mas sua regulamentação se efetivou de fato apenas em 1965, com o Parecer 977/65' , aprovado pelo Conselho Federal de Educação. Em sua primeira fase de expansão, na década de 70, a pós-graduação teve como público formativo principal os próprios docentes das universidades brasileiras, e organizava-se em torno de três objetivos principais: "1) formar professorado competente para atender à expansão quantitativa do Ensino Superior; 2) estimular o desenvolvimento da pesquisa científica por meio da preparação adequada de pesquisadores; e 3) assegurar o treinamento eficaz de técnicos e trabalhadores intelectuais para atender às necessidades do desenvolvimento nacional em todos os setores" (BRASIL, 1965).

Nesse período, a formação de docentes nos programas de pós-graduação, principalmente em nível de mestrado, tornava-se condição para atualização do quadro de professores na universidade. Assim, os programas receberam a tarefa de aprimoramento do ensino e da pesquisa nas instituições de ensino superior por meio do aperfeiçoamento de seu corpo docente.

De acordo com Schapochnik (2007), esse momento representou um dos três "momentos decisivos" da história da leitura no Brasil, pois, a partir de então, ter-se-ía estabelecido um processo de especialização das pesquisas sobre o tema, contribuindo para esse processo, além do desenvolvimento dos programas de pós-graduação, também a criação das agências de fomento, que permitiram a expansão da pesquisa acadêmica individual e coletiva sobre leitura e também sobre seu ensino. Ainda sobre esse contexto, Silva (1983) considerava haver

um verdadeiro renascimento dos estudos relativos aos problemas de leitura do povo brasileiro. Interessante notar que essa tendência da pesquisa ultrapassa o mundo da pseudo-concreticidade dos fatos sociais (entre eles, a leitura) através da crítica do idealismo e dos outros “-

\footnotetext{
${ }^{1}$ Esse parecer contribuiu para estabelecer, pela primeira vez, o formato institucional básico da pós-graduação brasileira: trazendo uma distinção entre o mestrado e o doutorado, estabelecia uma relação de continuidade, ou seja, o mestrado seria pré-requisito para o doutorado.

${ }^{2}$ Schapochnick (2007) descreve três momentos que considera decisivos para a história da leitura. O primeiro momento compreende um conjunto de textos publicados entre as décadas de 1940 e 1950 em que se apresentam representações e práticas de leitura. O segundo momento corresponde aos anos de 1970, quando há a emergência de revistas especializadas voltada para a comunidade universitária e para a divulgação do conhecimento acadêmico. Por fim, o terceiro e último momento remete aos anos de 1980 e é marcado pela consolidação de programas de pós-graduação implantados nos anos de 1970, após a reforma universitária.
} 
ismos" que impregnaram a ciência na década anterior e através da ação dirigida à formação de leitores e melhoria da leitura. É interessante observar ainda que atualmente a preocupação em torno da problemática da leitura envolve não só educadores e psicólogos, mas também filósofos, antropólogos, sociólogos, bibliotecários, linguistas e produzindo bons conhecimentos na área da leitura através de óticas interdisciplinares (SILVA, 1983, p.80).

De acordo com o autor, o crescimento quantitativo e qualitativo dos estudos sobre leitura naquele momento parecia ter sido resultado de um conjunto de fatores, dentre os quais o "amadurecimento" dos cursos de mestrado e de doutorado, a partir de novas abordagens para a análise dos objetos de pesquisa; a criação de linhas de pesquisa mais relevantes e o combate à neutralidade da pesquisa científica; as novas definições de leitura que apresentavam o ato de ler como instrumento de libertação e de transformação social; e a proposição de teorias que buscavam superar os dados empíricos, considerados como superficiais, com a perspectiva de ampliar as possibilidades explicativas e de compreensão do fenômeno da leitura.

Todos esses fatores, segundo Silva (1983), foram importantes para impulsionar a melhoria na qualidade da difusão e da circulação dos resultados de pesquisas sobre o tema. Teria contribuído também para esse processo a realização de congressos e de seminários que abriram espaços para o debate e mobilizaram especialistas de diferentes áreas do conhecimento a colocar em discussão questões relativas às abordagens teóricas e práticas acerca da leitura e seu ensino.

Assim, o Congresso de Leitura (COLE) trouxe como tema a ser debatido a censura imputada à leitura pelo regime ditatorial e a necessidade de apontar novas possibilidades ao desenvolvimento das práticas leitoras e da formação de leitores. Na conferência de encerramento desse primeiro Congresso, Gadotti (1979) apontava que

Seria preciso, a meu ver, que esse congresso de Leitura se transformasse num Congresso de Leitura Popular, que defendesse os interesses dos leitores postergados. Não basta saber ler se os veículos de leitura são inacessíveis, financeira e culturalmente, à massa da população. Ler é uma necessidade social, um bem social e, portanto, deve ser garantido pelo Estado[...] (GADOTTI, 1979, p.45).

A produtividade e relevância dos debates, reflexões e produção de resultados de pesquisa acerca do ensino de leitura, nesse período, se evidenciam também quando se observam as publicações em livros que se tornaram referências para as proposições teórico-metodológicas e para as práticas de ensino de leitura no país. São publicados no período: $O$ Ato de Ler: fundamentos filosóficos e psicológicos da leitura, de Ezequiel Theodoro da Silva, com primeira edição em 1981 (SILVA, 1981); A crise da leitura - as alternativas do professor, organizada por Regina Zilberman, obra que teve sua primeira edição em 1982 (ZILBERMAN, 1982); A Importância do Ato de Ler - três artigos que se completam, de Paulo Freire, com a primeira edição em 1982 (FREIRE, 1982); Leitura e Realidade Brasileira, de Ezequiel Theodoro da Silva, com primeira edição em 1983 (SILVA, 1983); capítulos de O texto na sala de aula, organizado por João Wanderley Geraldi, com primeira edição em 1984 (GERALDI, 1984); e O Aprendizado da Leitura, de Mary Kato, com primeira edição em 1985 (KATO, 1985). Além das publicações em livro, acontecimento de importância para a expansão dos debates e estudos a respeito do 
ensino de leitura foi também a publicação da Revista Leitura: Teoria e Prática, que teve seu número zero publicado em 1983 (SILVA, SILVA \& OLIVEIRA, 2017).

Considerando-se, portanto, o contexto de expansão das pesquisas em nível de pósgraduação, de ampliação do acesso à escolarização básica pública, e de lutas por transformações sócio-político-econômicas no país, foram analisadas dissertações de mestrado defendidas em instituições públicas e particulares, entre 1983 e 1989 com o objetivo de conhecer de que modo a leitura e seu ensino se constituíram em objeto de pesquisas acadêmicas no país, naquele contexto.

\section{Fundamentação teórica e metodológica}

A produção e análise dos dados, no presente trabalho, se desenvolveram segundo perspectiva discursiva de linha francesa, com base em conceitos propostos por Maingueneau $(1997 ; 2005)$ sobre os processos de constituição dos discursos. Segundo o autor, os discursos se constituem em relações interdiscursivas, fundamentadas em processos de delimitação recíproca.

O analista, de sua posição, estabelece recortes no campo discursivo que se lhe apresenta. O campo discursivo é um conjunto de discursos que se interconstituem e compõem parte restrita do universo discursivo, conjunto finito, mas incomensurável, dos discursos existentes num dado momento histórico. Num campo discursivo identificável, o analista recorta o espaço discursivo a que vai se dedicar, formado pelos discursos em processo de delimitação recíproca cujo processo de constituição objetiva conhecer.

Os discursos que se delimitam num mesmo espaço discursivo guardam entre si relação genética, considerando-se que os enunciados se constituem como respostas a enunciados que os precederam (BAKHTIN, 1997). No processo de delimitação recíproca que assim se estabelece, os discursos se diferenciam (e se definem, desse modo, suas identidades) com base em regras semânticas que estabelecem o que pode e o que não pode ser dito, i.e., os enunciados legitimáveis num dado discurso. Os enunciados denegados ou recusados de acordo com suas regras semânticas são atribuídos negativamente ao discurso posicionado na função de concorrente ou de adversário, do qual se constroem simulacros, i.e.: traduzem-se seus enunciados segundo as regras do discurso em posição de agente, o que evidencia a incompreensão que se estabelece entre o que se enuncia num discurso e em outro - fenômeno que Maingueneau (2005) denomina interincompreensão.

A hipótese que orientou a análise dos dados no presente trabalho é a de que, no caso da leitura, por já haver discursos acadêmicos sobre seu ensino desde os momentos finais do século XIX (MEDEIROS, 2019), as pesquisas desenvolvidas na década de 1980 não se posicionaram contrariamente ao que tem sido caracterizado negativamente como ensino tradicional nos discursos de renovação do ensino no país (Pietri, 2003), mas se posicionaram de modo que a tradição escolar, nesse caso, não fosse representada como um adversário em relação ao qual polemizar, mas como uma memória que deveria ser resignificada, em função do contexto histórico que se constituía naquele momento, e com base em recursos teórico-metodológicos mais recentemente produzidos em pesquisas acadêmicas.

A análise dos dados se orientou pela hipótese, portanto, de que o ensino de leitura se constituiu em objeto de pesquisa com base em polêmicas (MAINGUENEAU, 2005) estabelecidas pelo discurso acadêmico sobre ensino de leitura com relação às práticas escolares para a formação de leitores existentes no momento histórico de desenvolvimento das pesquisas observadas. Nesse processo discursivo, a constatação de que o ensino de leitura na escola teria se degradado evidenciaria a necessidade de renovação dos recursos teórico-metodológicos, que seriam então produzidos pelos pesquisadores na academia e ofertados aos professores da escola básica pública, para que, transformando-se as práticas docentes, se alterasse o quadro de crise na leitura que teria se instaurado no país. 


\subsection{A constituição do corpus de análise}

O material de análise é composto de dissertações de mestrado que respondessem ao escopo estabelecido para a pesquisa: o ensino de leitura nos níveis relativos ao ensino fundamental II, o antigo ginásio, e ao ensino médio, o antigo colegial. Não se observa o nível referente ao ensino fundamental I, o antigo primário, em razão de os estudos sobre este período da escolarização vincularem-se mais fortemente aos processos de alfabetização de que ao desenvolvimento das competências de leitura.

A partir de levantamentos bibliográficos em repositórios como a biblioteca de teses e dissertações da Coordenação de Aperfeiçoamento de Pessoal de Nível Superior CAPES; em sites de bibliotecas de Institutos e Faculdades de Instituições de Ensino Superior brasileiras; e com base em informações obtidas nas próprias referências bibliográficas das dissertações que gradualmente eram inseridas no conjunto de documentos que compuseram o material de análise, estabeleceu-se o conjunto composto por doze dissertações de mestrado defendidas entre os anos de 1983 e 1989 em universidades públicas e privadas do país:

D1 - Contribuição ao Ensino de Leitura. Denise Grein dos Santos. Mestrado em Educação, Universidade Federal do Paraná (UFPR), 1983.

D2 - A Escolarização do Leitor: a didática da destruição da leitura. Lílian Lopes Martins da Silva. Mestrado em Educação. Universidade Estadual de Campinas (UNICAMP), 1984. D3 - Leitura e Formulação de Textos Didáticos: investigação dos efeitos de coesão na compreensão de leitura. Iuta Lerche Vieira Rocha. Mestrado em Educação. Universidade Federal do Ceará (UFC), 1985.

D4 - Leitura e Consciência: princípios para uma leitura escolar pedagógica. José Lourival Ferrazza. Mestrado em Educação. Universidade de São Paulo (USP), 1986.

D5 - Texto Literário e Contexto Didático: os (des)caminhos na formação do leitor. Emília Amaral. Mestrado em Teoria Linguística. Universidade Estadual de Campinas (UNICAMP), 1986.

D6 - Em busca de fatores determinantes da Leitura Crítica. Maria Guadalupe de Castro. Mestrado em Ciências Humanas: Língua Portuguesa. Pontifícia Universidade Católica de São Paulo (PUC-SP), 1987.

D7 - A Leitura Compreensiva. Zélia Maria José Fernandes. Mestre em Ciências Humanas: Língua Portuguesa. Pontifícia Universidade Católica (PUC-SP), 1987.

D8 - Leitura, Literatura e Escola: subsídios para uma reflexão sobre a formação do gosto. Maria do Rosário Mortatti Magnani. Universidade Estadual de Campinas (UNICAMP), 1987.

D9 - O Ensino de Leitura como reflexo de Teorias Linguísticas de Leitura: uma crítica. Sandra Maria Penteado Ferreira Castro. Mestrado em Linguística. Universidade Estadual de Campinas (UNICAMP), 1988.

D10 - Proposta para o Ensino de Leitura. Sueli Sant'Anna. Mestrado em Ciências Humanas: Língua Portuguesa. Pontifícia Universidade Católica (PUC-SP), 1988.

D11 - Ensino de Leitura no $1^{o}$ grau: uma proposta sob o enfoque argumentativo. Cacilda Tavares. Mestrado em Ciências Humanas: Língua Portuguesa. Pontifícia Universidade Católica (PUC-SP), 1988.

D12 - Formação do Leitor: um projeto pedagógico para a sala de aula. José Luís Pieroni Rodrigues. Mestrado em Educação. Pontifícia Universidade Católica (PUC-SP), 1989. 
O período histórico observado na pesquisa, quando se produziram as primeiras investigações em nível de mestrado sobre leitura no país, foi delimitado considerando-se as publicações que inauguram, no início dos anos 1980, os discursos de renovação teóricometodológica para a formação de leitores e para a promoção da leitura no país, até os momentos finais dessa década, quando, com a abertura política, os discursos pela transformação social e econômica passaram a concorrer com discursos de caráter neoliberal, o que reordenou as bases semânticas em que foram produzidas a partir de então as proposições acadêmicas, pedagógicas e curriculares no Brasil (FREITAS, 2004).

\section{Análise dos dados}

A análise dos dados possibilitou observar-se um modo de funcionamento discursivo comum às dissertações quanto aos processos de constituição de seus objetos de pesquisa: nelas, evidencia-se uma organização em que se parte da caracterização de uma crise da leitura, com base em que se tematizam as condições de trabalho e as práticas docentes na escolarização básica pública, a que se destinam então as propostas de ensino de leitura produzidas pelos autores das pesquisas. Esses três elementos constitutivos das pesquisas analisadas serão observados a seguir.

\subsection{A identificação de uma crise da leitura}

Um elemento recorrente nos documentos que compõem o corpus de análise é a afirmação de que na escolarização básica estaria sendo produzido um descompasso entre o ensino de leitura e as práticas de leitura socialmente valorizadas, o que conduziria milhares de pessoas à marginalização cultural. Nas dissertações analisadas, é estabelecida relação causal entre o desempenho em leitura e o insucesso escolar, e entre as dificuldades do leitor e o fracasso na escola:

A constatação de que o insucesso escolar do aluno está intimamente ligado ao seu desempenho em leitura tem sido apontada por inúmeros pesquisadores e estudiosos contemporâneos. (D3, 1985) ${ }^{3}$

O fracasso na escola é mediado, em grande parte, pelas dificuldades de leitura. Tais dificuldades, por sua vez, passam também pelo tipo de texto proposto como material de leitura. (D 3, 1985)

A leitura na escola é eixo do processo educativo. Vimos relação dela com o fracasso escolar. Fora dos muros da escola, numa sociedade cada vez mais letrada, é relevante um eficiente desempenho linguístico do cidadão, pois toda atividade cultural passa de alguma maneira e em algum momento pelo texto escrito. (D12, 1989)

Causa do insucesso escolar, o ensino da leitura seria, em decorrência, um problema social e político. Nesse sentido, a escola seria a responsável por não promover atividades de leitura de modo satisfatório ou suficiente, o que seria um impeditivo para que se realizassem práticas de ensino de leitura que permitissem o aprendizado escolar de suas características socialmente valorizadas:

\footnotetext{
${ }^{3}$ Encontram-se marcados em negrito os destaques realizados neste momento, nas passagens transcritas, para evidenciar elementos que sustentam o processo de análise dos dados. Os destaques presentes originalmente nas passagens transcritas se encontram marcados em itálico.
} 
Nesse quadro, a leitura foi praticamente excluída pelo seu próprio esfacelamento. Pouco ou nada restou para esse campo do ensino de língua materna: um trabalho improvisado com meia dúzia de textos sobre os quais se fazem outra meia dúzia de perguntas a título de 'interpretação' e 'conhecimento gramatical'. Assim a escola reduziu a leitura, como os demais componentes do ensino da língua materna, a um conhecimento que chamaríamos 'escolar' da língua, a uma tarefa escolar, a um conhecimento burocrático, sem relação com a vida fora da escola. (D12, 1989)

Observa-se, na passagem acima, a consideração de um momento anterior em que o ensino de leitura teria sido realizado de modo satisfatório, para, no momento em que se produz o estudo sobre o tema, apontar-se um declínio na qualidade desse ensino.

A responsabilização pela qualidade da formação leitora, nesse contexto, não é atribuída ao professor, mas às condições trabalho docente então existentes, as quais teriam se degradado desde um momento anterior mais bem estruturado, até o momento de produção da pesquisa:

No entanto, embora eu reconheça o grande significado dos 'mecanismos intra-escolares' na explicação dos problemas dessa natureza, sei também que o professor, figura que personifica esses mecanismos, é mais vítima do que culpado por essa situação, porque não se pode ignorar a cadeia de alienações a que foi duramente submetido. (D2, 1984)

Da mesma forma e pelos mesmos motivos, assistimos todos, nesse período, a um processo de desvalorização dos profissionais do ensino que tiveram uma perda salarial da ordem de $238,8 \%$ entre os anos de 1964 a 1983. Mal remunerados, impedidos de se organizar enquanto categoria, por verem cassados os seus direitos de reunião e de luta e por serem obrigados a correr de escola em escola, atolando-se de aulas. Premiados com uma 'modernização' dos currículos e programas das suas disciplinas, mas impedidos de estudar e atualizar-se, estes professores não podem carregar nas costas o ônus dessa crise geral. (D2, 1984)

A escola é observada como estando num processo de degradação em direção à condição de precariedade constatada no momento em que se desenvolve a pesquisa, sendo até mesmo atribuída ao termo escolar carga semântica negativa, utilizando-se essa palavra para qualificar o ensino mal realizado. A qualificação negativa da escola básica, autoritária, pobre e decadente, evidencia-se ainda no questionamento mesmo de seu estatuto pedagógico:

Se a leitura é responsabilidade da escola, dessa escola autoritária e burocraticamente instituída, em situação de penúria e decadência, que a essa responsabilidade só pode responder na forma de arremedo, é possível e desejável nela ensinar a ler? (D2, 1984)

Embora surjam novas metodologias e haja preocupação com o ensino da leitura, a ação escolar é falha e desmotivante. (D1, 1983) 
Nos enunciados em análise, é possível observar que o ensino tradicional de leitura é caracterizado positivamente, como um passado anterior à decadência que levou ao estado em que a escola não mais proporcionaria o aprendizado da leitura, ainda que novos recursos metodológicos fossem ofertados. Assim, nas pesquisas observadas, atribui-se o insucesso escolar ao inadequado tratamento que a leitura receberia por parte da escola que se constituía naquele momento histórico, em que assumiria um caráter utilitário:

Toda essa dinamicidade do processo de leitura, no entanto, acaba, muitas vezes, ficando fora da escola, onde a leitura assume finalidades imediatistas e utilitárias, tais como: ler para fazer exercícios de interpretação, para estudar itens de conteúdos, para adquirir modelos de escrita, para gostar e se habituar, para conscientizar e politizar. (D8, 1987)

Por inúmeras razões, dito e sentido por muita gente, existe uma aguda crise na capacidade de ler textos escritos. Apesar de alfabetizados, muitos jovens e adultos apresentam, hoje em dia, carência dessa habilidade básica. Somada com as deficiências também na capacidade de expressão verbal, estamos diante de um quadro desalentador no que diz respeito às habilidades comunicativas básicas. (D12, 1989)

Constatada a insuficiente formação escolar com que os alunos sairiam das escolas, fazem-se referências, nos trabalhos observados, a atividades de leitura realizadas sem objetivos definidos, marcadas pela ausência de critérios na execução das atividades. Reconhecida a existência de uma crise na aprendizagem e no desenvolvimento das atividades de ensino de leitura na escola, atribui-se a essa instituição a responsabilidade pela superação da situação então em vigência, o que demandaria sanear o ensino praticado:

A escola precisa adotar medidas saneadoras da 'crise' do ensino que também tem afetado o campo da leitura, o que vem sendo detectado através do fraco desempenho do aluno-leitor. (D7, 1987)

A oferta de subsídios teórico-metodológicos renovados poderia contribuir para melhorar as práticas de sala de aula. Tais recursos viriam em auxílio do professor para superar a crise na leitura que então estaria em vigência. Ao se apresentarem propostas para o trabalho pedagógico, a leitura é considerada de modo a se destacar sua importância para o desenvolvimento pessoal do aluno-leitor, de seu gosto e hábito de ler, possibilitando desde a aquisição de conhecimentos até a produção de instrumentos para a transformação da sociedade. A leitura é considerada também recurso fundamental para a formação escolar, pois práticas leitoras proficientes favorecem o aprendizado em todas as disciplinas do currículo.

Defende-se, assim, a necessidade de o interesse pela leitura ser cultivado nas atividades realizadas na escola, o que poderia ser conseguido com o desenvolvimento do hábito de ler, que é considerado garantia de acesso à informação, ao conhecimento, e de maior participação na sociedade moderna:

Daí a preocupação em analisar a leitura em sua abrangência: como fator de desenvolvimento pessoal e profissional, como despertar o interesse e, consequentemente, incutir o hábito de ler. Importante verificar o aspecto pedagógico, a metodologia utilizada na escola e sua eficiência, a atuação do professor na vida intelectual do indivíduo. (D1, 1983) 
A leitura é um fator essencial do processo educativo. É o melhor procedimento que o aluno utiliza para penetrar no imenso campo de possibilidades que a ciência e a cultura lhe oferecem. (D11, 1988)

A leitura é considerada uma atividade-meio para o desenvolvimento de outras atividades. É concebida uma atividade essencial pelo que o seu exercício possibilita ao desenvolvimento de outras habilidades, principalmente as relacionadas à comunicação escrita.

Ao considerá-la como instrumento de inserção no campo da ciência e da cultura, a leitura seria entendida como forma de acesso ao conhecimento, apontando para a necessidade de formação do leitor desde o início da escolarização. Tal formação se realizaria pela interação com o texto, e teria como principal agente o professor da educação básica.

\subsection{A interlocução com o professor da escola básica}

Nas dissertações analisadas, as referências ao professor da escola básica posicionam-no como um dos principais destinatários projetados das propostas pedagógicas produzidas pelos pesquisadores, ainda que o destinatário primeiro das pesquisas acadêmicas possam ser outros pesquisadores que tenham interesse no tema. A divisão de responsabilidades parece ser uma estratégia para que o enunciador tenha a adesão de seu leitor projetado às propostas pedagógicas que apresentará com objetivos de contribuir para mudanças nas práticas de ensino. Nesse sentido, por vezes associam-se, em um mesmo sujeito, a figura do professor e a figura do pesquisador, como se pode observar na passagem a seguir:

Caro professor de Língua Portuguesa de $1^{\circ}$ grau, meu colega de trabalho. Estou convencido de que ler não é uma atividade como as outras, muito menos na escola. Poucas atividades como essa, têm tanto sentido, tem tanto a ver com a vida e as pessoas. Isso é que me moveu a intercalar o avental do professor com os dados de uma pesquisa. Foi sempre essa consideração: a de que a leitura como um dos eixos do processo escolar tanto pode ser um instrumento essencial na aprendizagem de outros conhecimentos como pode ser considerada pelo efeito que ela representa no desenvolvimento cognitivo do aluno e, portanto, em sua vida (D12, 1989).

Nessa passagem, a representação discursiva do professor se constrói em dois diferentes momentos. No primeiro momento, quando o pesquisador utiliza-se da expressão caro professor para se dirigir a seu leitor, imprime-se uma diferenciação entre a posição ocupada pelo enunciador no campo da pesquisa, e a posição daquele a quem se dirige, o professor da escola básica, para, logo em seguida, ser apresentada a identificação entre um enunciador e outro no mesmo locutor ${ }^{4}$, de modo que a pesquisa sobre leitura contribuísse para sua prática de ensino.

Com base na relação de proximidade construída discursivamente em relação a seu leitor projetado, o pesquisador dirige então sua proposta pedagógica ao professor, seu colega, considerado interlocutor da pesquisa. Nesses momentos, reafirma a necessidade de desenvolvimento de práticas específicas de leitura para a formação do leitor. Esse objetivo é explicitado na passagem a seguir, em que se evidencia a tentativa de solucionar os problemas a partir do interior da sala de aula:

\footnotetext{
4 Faz-se aqui menção à teoria polifônica proposta por Ducrot (1987) segundo a qual aquele que se responsabiliza pelos dizeres, o locutor, organiza enunciativamente as vozes atribuídas a determinados enunciadores, que expressam pontos de vista distintos.
} 
Devo reiterar que este trabalho não visa à busca de soluções globais sistemáticas nem governamentais, mas sim ao auxílio ao professor no seu planejamento na sala de aula, no seu trabalho concreto em relação à atividade de leitura, cuja implementação depende apenas da sua opção pedagógica e política [...]. (D4, 1986)

Nesse sentido, a busca pela reconstrução de um ensino de leitura que recuperasse a qualidade que teria caracterizado tradicionalmente esse ensino se realiza com base na oferta de subsídios teórico-metodológicos que promovessem transformações pedagógicas a partir da sala de aula, do trabalho do professor, apesar das condições adversas para 0 desenvolvimento desse trabalho:

Para tanto, é necessário que se supere a artificialidade que impregna o ensino de leitura, possibilitando o verdadeiro raciocínio e a reflexão, permitindo a análise crítica e a ação, visando a estabelecer um novo rumo para o ensino em sala de aula. Sugere-se, para tanto, um relacionamento mais participante entre o professor e o aluno, através da troca de experiência e um diálogo constante entre leitor/texto/autor. (D11, 1988)

$\mathrm{Na}$ passagem acima, observa-se a relação polêmica estabelecida entre o discurso acadêmico e a representação que neste se constrói da prática escolar no ensino da leitura: esta prática se caracterizaria pela artificialidade, que impediria a relação com a verdade, 0 desenvolvimento do raciocínio e reflexão, e a formação crítica dos leitores destinada à ação social. O trabalho em sala de aula dependeria de formação suficiente do professor, de modo que pudesse atender às necessidades que verificasse junto aos alunos, o que significa, neste caso, posicionar-se em acordo com o que se representa positivamente no discurso acadêmico a respeito do que seja a leitura e seu ensino.

A fim de que o leitor projetado se posicione em relação a que grupo pretende pertencer - dos professores comprometidos ou dos descomprometidos com a qualidade do trabalho docente -, a imagem do professor é então construída opondo-se as características negativas às positivas, discriminando-se modos distintos de recepção das propostas de renovação pedagógica ofertadas nas pesquisas:

Se há uma minoria de professores de Língua Portuguesa que tenta mudar os procedimentos didáticos, há, por outro lado, os acomodados com a situação; outros insatisfeitos, às vezes amedrontados com as mudanças que são urgentes e necessárias. A formação que receberam baseava-se em conceitos que necessitam de reformulação para se atingir os objetivos reais do ensino. E na realidade, podemos concluir que a maioria desconhece novos procedimentos para o ensino de leitura, muitas vezes, por não conseguirem aperfeiçoar-se por falta de condições. (D10, 1988)

À representação negativa contrapõe-se outra que projeta a necessidade de que o professor tenha formação condizente em qualidade com o grau de responsabilidade que possuiria em seu trabalho de formação de leitores: 
O professor ocupa lugar de prestígio na formação do aluno e na tarefa pedagógica. É ele que, com suas características individuais, incentiva, motiva, desperta, o interesse, o espírito de pesquisa e baliza as aulas de leitura. Necessário, de conseguinte, professores capazes, criativos, ornados de boa formação profissional e preocupados com sua atuação. São, numa palavra, os responsáveis diretos pelo sucesso do ensino de leitura. (D1, 1983)

Entre a caracterização negativa e a caracterização positiva, propõe-se a necessidade de mudanças nas práticas de sala de aula, e, portanto, na formação do próprio professor, que seria o agente principal responsável por essas mudanças. A formação crítica do leitor passaria pela formação crítica do próprio professor, o que lhe possibilitaria tomar criticamente sua própria prática:

Parece-me que a saída coerente para o professor pode ser buscar uma 'práxis' compartilhada que lhe ofereça segurança e permita uma interferência crítica. Cabe ao educador romper com o estabelecido, propor a busca e apontar o avanço, para além da dicotomia valorativa entre quantidade ou qualidade. Para isso, é preciso problematizar o conhecido, transformando-o num desafio que propicie a mobilidade. (D8, 1987)

A referência ao professor é feita, assim, não somente quando se aponta a necessidade de sua formação continuada, mas também ao atribuir a ele a responsabilidade por ultrapassar os modos comuns e cotidianos de trabalho em sala de aula, buscando novos métodos de ensino, novas possibilidades para o ensino da leitura.

É considerada responsabilidade do professor, então, preparar-se para desenvolver o trabalho com a leitura em sala de aula, de modo a promover transformações, dado que caberia ao educador romper com o estabelecido. A referência ao professor passa, portanto, tanto pelo aspecto pedagógico, pelas situações relativas ao ensino de leitura na sala de aula, como pelo aspecto político, no que diz respeito à organização profissional em torno de melhores condições de trabalho, e, ainda, pelas relações estabelecidas com a legislação educacional e os documentos oficiais de referência curricular:

Uma consequência do isolamento que tem caracterizado as várias instâncias do sistema escolar brasileiro é que o suposto interlocutor de uma Proposta ${ }^{5}$ deste tipo, o professor de $2^{\circ}$ grau, acaba transformando-se em seu mero receptor, ou talvez nem isso, já que seus níveis de expectativa, suas condições de trabalho, sua diversidade de formação e de clientela, são aparentemente desconsiderados no processo de elaboração de orientações que, paradoxalmente, devem nortear-lhe a conduta profissional. (D5, 1986)

O objetivo parece ser o de garantir que o professor do ensino básico tivesse condições de trabalho que lhe garantissem a possibilidade de apropriação crítica das diretrizes pedagógicas que lhe seriam destinadas em sua formação inicial e continuada. Nesse sentido, ainda que se considerassem as condições adversas a que estariam sendo submetidos os docentes em seu trabalho, essas condições poderiam ser transformadas desde que as mudanças nas práticas

\footnotetext{
${ }^{5}$ Trata-se da Proposta Curricular de Língua Portuguesa e Técnicas de Redação para o $2^{\circ}$ grau (São Paulo, 1978).
} 
pedagógicas se realizassem pelo professor em sua atuação acadêmica, social e política. As relações polêmicas que se estabelecem no discurso em análise se constituem, assim, a partir das contraposições entre as propostas acadêmicas de caráter científico para o ensino de leitura, com os recursos de criticidade que ofereceriam, e as práticas pedagógicas que então se realizavam na escola básica, caracterizadas como defasadas, ineficientes e sem qualidade.

Os pesquisadores propõem-se então a produzir e ofertar recursos de ensino fundamentados em bases teórico-metodológicas renovadas que pudessem auxiliar na solução dos problemas encontrados em contexto escolar. Desse modo, seria possível levar à sociedade mais ampla os saberes produzidos no contexto acadêmico, uma vez que esses poderiam contribuir para recuperar a qualidade no ensino de leitura e fundamentar propostas pedagógicas que auxiliassem a transformar a realidade escolar.

\subsection{As propostas de renovação do ensino de leitura na escola básica}

A formalização e a apresentação de propostas para o ensino da leitura na escola básica se fazem com base em referenciais teóricos e metodológicos qualificados como inovadores, renovados, mais adequados para fundamentar o processo de mudança que se julgava necessário nas práticas de ensino, tendo como ponto em comum o objetivo de formar o leitor crítico. De um modo geral, as dissertações analisadas apontam para a utilização de teorias linguísticas situando-as como fundamentação teórica das pesquisas realizadas, como pode ser observado na passagem a seguir:

Este trabalho nasceu de uma preocupação em estudar a leitura tanto no seu aspecto teórico quanto prático. Mais especificamente, preocupamo-nos em estudar como o ensino de leitura reflete, e com que consequências, as correntes teóricas de leitura desenvolvidas pela linguística. (D9, 1988)

Os conhecimentos produzidos pelos estudos linguísticos possibilitaram a constituição de novas perspectivas no desenvolvimento das pesquisas sobre ensino de leitura. Nas dissertações analisadas, contribuições da Linguística, e de suas vertentes, como a psicolinguística, a sociolinguística, a pragmática, a teoria da enunciação ou a análise do discurso, são agenciadas para o tratamento dos temas e objetos de pesquisa e para a fundamentação de propostas de ensino e aprendizagem de leitura na escola básica. Os referenciais teóricos produzidos pelos estudos linguísticos ampliavam a compreensão dos elementos gramaticais para além dos aspectos fonológicos e morfossintáticos, o que possibilitava compreender-se o texto como uma unidade de sentido.

A proposta de alternativas se realizou então com o movimento do pesquisador em seu trabalho de apropriação de subsídios teóricos, que, agenciados, fundamentaram a proposição de práticas de leitura consideradas satisfatórias para a constituição de um ensino de fato democrático e transformador.

É o que pode ser observado em uma das dissertações cujo objetivo é o de elaborar uma proposta para o ensino de leitura destinada a alunos de $5^{\mathrm{a}}$ a $8^{\mathrm{a}}$ séries (atuais $6^{\circ}$ a $9^{\circ}$ anos), "tendo em vista, a formação do leitor crítico e amadurecido". O trabalho em sala de aula envolveria mais diretamente o objetivo de

Formalizar uma proposta para o ensino de leitura, visando à formação do leitor crítico e amadurecido que deve desvelar o texto, associar ideias, apresentar seu posicionamento crítico diante das ideias veiculadas por ele, 
dialogar com professor, colegas, texto e autor, recriar o texto através da possibilidade de várias leituras, produzir novos textos. (D 10, 1988)

Ao apresentar sua proposta, o pesquisador justifica a opção teórica escolhida com base no fato de que, com sua aplicação, seria possível que o ensino de leitura conseguisse atingir mais facilmente a finalidade de formar o leitor maduro e crítico, num processo contínuo e gradativo que precisaria ser iniciado desde as primeiras séries do $1^{\circ}$ grau, considerando-se em cada etapa de escolarização o nível de compreensão dos alunos-leitores.

O trabalho de leitura poderia ser concebido como se desenvolvendo em duas fases distintas: uma de compreensão e outra de interpretação. Para elaborar a proposta de ensino, teriam sido considerados o nível de escolaridade dos alunos e a evolução gradativa das dificuldades apresentadas por eles durante as atividades, dificuldades que se originariam da falta de hábito do aluno em se preocupar com elementos argumentativos no processo de leitura. Objetivo semelhante se observa em outro dos trabalhos analisados, em que se apresenta como finalidade da pesquisa:

Elaborar uma proposta de ensino de leitura, na qual o estudo do texto possibilite a formação desse leitor, que deve não só buscar o significado pretendido pelo autor, reagindo, questionando, enfim, apreciando com criticidade, posicionando-se diante das ideias veiculadas pelo texto, mas também considerar a mensagem escrita como a possibilidade para a reflexão e recriação, levando à produção de novas leituras, revelando o caráter libertador do ato de ler, em que o leitor se conscientiza de que é importante compreender e associar os novos conhecimentos adquiridos através do texto ao seu conhecimento de mundo, ampliando-os, como também assumir, perante o texto, uma atitude crítica. (D11, 1988)

Compreendendo que o ensino de leitura é um fator essencial do processo educativo, defende-se, na pesquisa em questão, a importância do ensino de leitura como um modo de desenvolver a capacidade de relacionar um texto lido a outros. Observa-se que o ensino de leitura é considerado como tendo diferentes funções, seja para possibilitar o estudo de texto, seja para ampliar a compreensão leitora que se desenvolve pela reflexão e pela recriação, tendo como objetivo fundamental possibilitar que o/a estudante assuma uma atitude crítica diante do texto lido.

O projeto pedagógico renovado que orientaria a formação leitora pressupunha o contexto escolar como principal fator para o desenvolvimento de atividades de leitura, na medida em que a atuação sobre ele possibilitaria ampliar a entrada na escola das diferentes práticas sociais em que o ato de ler se materializa. Tais práticas renovadas demandariam a revisão das concepções de linguagem e de ensino vigentes, segundo as quais a língua seria entendida como instrumento de comunicação, reduzindo-se as atividades didáticas ao objetivo de capacitar os alunos a utilizar esse instrumento.

As concepções em torno da leitura se alterariam, portanto, para que se considerasse de fato a importância do ato de ler na vida dos alunos, e de modo a se elaborar uma metodologia de ensino em direção à leitura como prática de conscientização para a formação do leitor crítico.

Na passagem abaixo apresenta-se proposta para o ensino de leitura que possui como objetivo principal conferir uma função e uma sistematização à atividade da leitura escolar, tendo em vista que o ensino da leitura seria dificultado pela falta de orientação para a prática leitora na escola. As atividades de formação do leitor estariam sendo realizadas sem critérios, sem objetivos, o que ocasionaria uma insuficiente formação intelectual e social dos egressos da escolarização básica: 
Propugnamos, para a leitura escolar, como alternativa àquelas duas posturas, uma participação educador-educando dialógica e conscientizadora baseada nos princípios pedagógicos de Paulo Freire. Podemos dizer que este trabalho é uma tentativa de tornar-se um elo de ligação entre certas teorias e propostas pedagógicas, psicológicas e linguísticas - ou aspectos delas - e sua aplicação do trabalho cotidiano, concreto do professor, quanto à atividade de leitura. (D4, 1986)

Considerando-se esses elementos, o ensino da leitura deveria se orientar para uma prática que oferecesse subsídios aos alunos-leitores de modo a lhes possibilitar compreender a realidade em que vivessem. O ponto de partida para a elaboração da proposta, de acordo com o pesquisador, foi a busca por relacionar uma bibliografia para conscientização dos alunos sobre a realidade brasileira, um conjunto de textos a serem utilizados nas atividades a se desenvolverem em sala de aula. Para conseguir reunir essa bibliografia, o pesquisador recorreu a vários intelectuais, solicitando que indicassem cerca de cinquenta obras cuja leitura pudesse conscientizar os alunos a respeito da realidade do país ${ }^{6}$.

Utilizando-se dos princípios básicos da pedagogia de Paulo Freire, defende-se na dissertação que a relação entre educadores e educandos se estabeleça de modo que ambos possam se apropriar dos saberes produzidos no processo de ensino e de aprendizagem. Desse modo, seria garantida a tomada de consciência da realidade e a perspectiva de atuação nessa realidade. As sugestões fornecidas pelo trabalho se orientam pela opção em fazer com que os educandos sejam atuantes no processo educativo, o que se realizaria com base no diálogo crítico estabelecido na relação pedagógica. Nesse sentido, os momentos de decisão se fariam com a participação de todos, com o objetivo de que os educandos pudessem apropriar-se de modo crítico do conhecimento e que tivessem por princípio básico questionar e criticar o conhecimento e a realidade.

A metodologia de ensino que sustenta a proposta didática no trabalho orienta-se pela premissa de que "o educando deve junto com o educador ser sujeito do processo educacional e a atividade de leitura deve ser uma atividade problematizadora, envolvendo a realidade social dos alunos" (D4, 1986). Para o desenvolvimento dessa proposta são sugeridos alguns passos necessários à realização da atividade de leitura, e tais considerações são dirigidas de modo específico ao professor:

- Preparar-se para usar o texto, a partir da leitura, da identificação das ideias principais, determinando os objetivos da leitura, planejando atividades que complementem a leitura;

- Preparar o aluno para a atividade, expondo os objetivos e os métodos do trabalho, realizar e avaliar a atividade. (D4, 1986)

Evidencia-se, na passagem acima, a orientação para que o trabalho em sala de aula se realize de modo a sempre serem explícitos os objetivos e a organização das atividades a se realizarem. Esse caráter de explicitude seria a contraparte metodológica da perspectiva segundo a qual se considera a leitura como uma atividade pedagógica que tem eminentemente uma finalidade social, sendo politicamente transformadora.

Em sentido semelhante, encontra-se dentre os objetivos de uma das dissertações analisadas o de investigar quais os "fatores que contribuem para a ocorrência de uma leitura

\footnotetext{
${ }^{6}$ Desse modo, uma extensa bibliografia é sugerida na dissertação, com obras de diferentes áreas de conhecimento voltadas a conhecer a realidade brasileira. Dentre os autores que fizeram indicações para a referida bibliografia estão os professores Florestan Fernandes, João Cruz da Costa, Alfredo Bosi, Antônio Cândido e o jurista Dalmo de Abreu Dallari.
} 
crítica" (D6, 1987). Na pesquisa, situações reais de sala de aula são observadas, a fim de "possibilitar a captação do processo particular de interação verbal através da leitura crítica" (D6, 1987). O objetivo, a partir do que se observa no contexto investigado, seria o de "proporcionar subsídios para a pesquisa Linguística e para o ensino da leitura".

A investigação apresenta-se, assim, com a finalidade de contribuir tanto com as pesquisas que se desenvolvem no contexto acadêmico e que têm como foco a Linguística, de modo a investigar as relações entre as correntes teóricas e o ensino de leitura que se desenvolve na escola, quanto com a prática de sala de aula da escola básica. O objetivo da pesquisa aponta para duas direções, a acadêmica e a pedagógica, que se inter-relacionam em função de serem consideradas a partir de uma base comum para seu desenvolvimento: o contexto de ensino. Para atingir tal objetivo, a abordagem teórica fundamenta-se na noção de interação verbal associada à necessidade de se formarem leitores críticos.

Apresentam-se como resultados alcançados com a referida pesquisa a articulação entre as características individuais e as posições sócio-históricas que regulam essas características, pois se considera que, ao propor um ensino de leitura para a formação de leitores críticos, é necessário levar em conta os reflexos dessa articulação no uso linguístico:

Os resultados desta pesquisa mostraram que algumas características individuais e a posição sócio-histórica de cada leitor refletem-se no linguístico, através dos diferentes graus do aprofundamento dialético das relações de sentido. (D6, 1987)

Os resultados a que chegamos nesta pesquisa demonstraram que, na realidade, há uma articulação do fator sócio-histórico e de fatores individuais que levam à leitura crítica, uma vez que a própria crítica manifesta-se dentro de um todo coerente. (D6, 1987)

A leitura crítica é apresentada pelo pesquisador como um processo que se desenvolve sobre a tensão dialética que se instaura no momento de realização da leitura, pois, para que a compreensão aconteça, a leitura deveria se fundar no confronto entre os sentidos dados ao texto pelo autor e os sentidos captados pelo leitor.

A leitura crítica é concebida como uma habilidade que depende de um trabalho realizado na interação do individual com o social, ou seja: para a realização da leitura, é necessário que se exerça a capacidade do leitor em conferir relevância a certos fatores de significação do texto em função da situação em que a leitura se realiza.

Parte-se, assim, do princípio de que a inter-relação entre contexto situacional e usos da linguagem abre caminhos para várias possibilidades de significação e produção de sentidos, não se restringindo essas possibilidades de produção, em situações de leitura, apenas aos aspectos referentes ao texto e ao leitor, pois estariam relacionadas, principalmente, à posição sócio-histórica e ideológica em que se realiza o ato de ler. Assim, o desenvolvimento da leitura crítica se faria relacionado à ampliação do grau de consciência que seria desenvolvido pelos sujeitos ao trabalharem com aspectos associados à relação pensamento-linguagem e à relação linguagem-sociedade.

Mostra-se recorrente, assim, nas dissertações que compõem o corpus de análise, a orientação metodológica da formação leitora direcionada à produção e transformação do contexto social em que interagem os sujeitos da relação pedagógica. $\mathrm{O}$ desenvolvimento das condições sociais se sustentaria na formação de leitores críticos, conscientes de suas condições culturais, políticas e econômicas. A qualidade da leitura estaria associada, então, às possibilidades de atuação social que garantiriam ao leitor, em oposição à instrumentalidade e tecnicidade que foi conferida a essa habilidade nas concepções e propostas de escolarização realizadas no contexto do regime militar. 


\section{Considerações finais}

Partindo de uma perspectiva discursiva, a análise dos dados evidenciou nos documentos que compõem o corpus da pesquisa um modo de organização recorrente no que se refere ao trabalho de constituição do ensino de leitura em objeto de investigações acadêmicas: um processo em que, ao detectar-se a existência de uma crise, observam-se suas causas e efeitos em contexto escolar, para, em seguida, buscarem-se subsídios em produções acadêmicas de modo que fossem propostas soluções para os problemas encontrados. A tradição é representada como um período anterior em que a formação leitora teria sido feita mais satisfatoriamente, e a prática social da leitura teria se desenvolvido mais plenamente no país.

As discussões em torno da leitura na escola básica, bem como a formulação de propostas para que se alterassem essas condições, se inter-relacionam com os modos como percebida a função do ensino da leitura em contexto escolar, enfatizando-se sua importância para a vida em sociedade, tanto no que se refere à formação do aluno em suas competências enquanto leitor, quanto no que se refere à necessidade de que as práticas de leitura contribuam para formar cidadãos críticos.

Dos resultados das discussões em torno dos problemas encontrados nas práticas de sala de aula, propuseram-se possibilidades outras de se realizar o trabalho de formação de leitores na escolarização básica. A proposta de alternativas se realizou então com o movimento do pesquisador em seu trabalho de apropriação de subsídios teóricos, que, agenciados, fundamentaram a proposição de práticas de leitura consideradas satisfatórias para a constituição de um ensino de fato democrático e transformador.

\section{Referências}

BAKHTIN, Mikhail. Estética da criação verbal. São Paulo: Martins Fontes, 1997.

BRASIL. Conselho Federal de Educação. Parecer n 977/65. Definição dos cursos de pósgraduação. Brasília, DF, 1965.

BEISIEGEL, Celso de Rui. Os primeiros tempos da pesquisa em sociologia da educação na USP. Educação e Pesquisa, São Paulo, v.39, n.3, 2013, p.589-607. DOI: https://doi.org/10.1590/S1517$\underline{97022013005000010}$

DUCROT, Oswald. O dizer e o dito. Campinas: Pontes, 1987.

FREITAS, Luiz Carlos. A avaliação e as reformas dos anos de 1990: novas formas de exclusão, velhas formas de subordinação. Educação e Sociedade, Campinas, v.25, n.86, 2004, p.131-170. DOI: https://doi.org/10.1590/S0101-73302004000100008

FREITAS, Marcos Cezar. Desempenho e adaptação da criança pobre à escola: o padrão de pesquisa do CRPE-SP. Educação e Pesquisa, São Paulo, v.40, n.3, 2014, pp.683-698. DOI: https://doi.org/10.1590/s1517-97022014091590

FREIRE, Paulo. A importância do ato de ler. São Paulo: Cortez, 1982.

GADOTTI, Moacir. O que é ler? (ou "Pedagogia da Leitura versus Pedagogia da Censura"). In: Anais do $2^{\circ}$ COLE. Campinas, SP: UNICAMP, 1979. 
GERALDI, João Wanderley. O texto na sala de aula: leitura e produção. Cascavel: Assoeste, 1984.

LUFT, Celso Pedro. Língua e liberdade. São Paulo: Ática, 1985.

KATO, Mary. O aprendizado da leitura. São Paulo: Martins Fontes, 1985.

MAINGUENEAU, Dominique. Gênese dos discursos. Tradução de Sírio Possenti. Curitiba: Criar, 2005.

MEDEIROS, Rejane R. A. Representações do ensino da leitura: as aulas de português na escola secundária brasileira (séculos XIX e XX). 2019. 237 f. Tese (Doutorado em Linguística), Universidade Federal de São Carlos, São Carlos, 2019.

SÃO PAULO. Proposta Curricular de Língua Portuguesa e Técnicas de Redação para o $2^{\mathbf{0}}$ grau. São Paulo: SEE/CENP, 1978.

SCHAPOCHNIK, Nelson. Cicatriz de origem: notas para uma historiografia da leitura no Brasil. In: FILHO, Plínio M.; TENÓRIO, Waldecy (org.) João Alexandre Barbosa: o leitor insone. São Paulo: EDUSP, 2007.

SILVA, Ezequiel T. O ato de ler: fundamentos para uma nova pedagogia da leitura. São Paulo: Cortez, 1981.

SILVA, Ezequiel T. Leitura e Realidade Brasileira. Porto Alegre: Mercado Aberto, 1983.

SILVA, Lilian L. M.; SILVA, Ezequiel T.; OLIVEIRA, Luciane M. A revista Leitura: Teoria \& Prática - momentos no tempo. Leitura: Teoria \& Prática, Campinas, v. 35, n. 70, 2017, p.13-32. DOI: https://doi.org/10.34112/2317-0972a2017v35n70p13-32

SILVA, Tereza R. N.; ARELARO, Lisete R. G. Orientações legais na área de currículo, nas esferas federal e estadual a partir da lei 5.692/71. Cadernos Cedes, São Paulo, n.13, 1987, p.26-44.

SOARES, Magda B. Linguagem e escola: uma perspectiva social. São Paulo: Ática, 1986.

ZILBERMAN, Regina (org.). Leitura em crise na escola: as alternativas para o professor. Porto Alegre: Mercado Aberto, 1982.

Referências das dissertações que compõem o corpus de análise

SANTOS, Denise Grein. Contribuição ao ensino de leitura. Dissertação (Mestrado em Educação). Universidade Federal do Paraná, Curitiba, 1983.

SILVA, Lílian Lopes Martins. A escolarização do leitor: a didática de destruição da leitura. Dissertação (Mestrado em Educação). UNICAMP, Campinas, 1984.

ROCHA, Iuta Lerche Vieira. Leitura e formulação de textos didáticos: investigação dos efeitos da coesão na compreensão de leitura. Dissertação (Mestrado em Educação). Universidade Federal do Ceará, Fortaleza, 1985. 
FERRAZZA, José Lourival. Leitura e Consciência: Princípios para uma leitura escolar pedagógica. Dissertação (Mestrado em Educação). Universidade de São Paulo, São Paulo, 1986.

MAGNANI, Maria do Rosário Mortatti. Leitura, Literatura e Escola: subsídios para uma reflexão sobre a formação do gosto. Dissertação (Mestrado em Educação). Universidade Estadual de Campinas, Campinas, 1987.

REIS, Zélia Maria Fernandes dos. A leitura compreensiva. Dissertação (Mestrado em Língua Portuguesa). Pontifícia Universidade Católica de São Paulo, São Paulo, 1987.

CASTRO, Maria Guadalupe de. Em busca de fatores determinantes da leitura crítica. Dissertação (Mestrado em Língua Portuguesa). Pontifícia Universidade Católica de São Paulo, São Paulo, 1987.

AMARAL, Emilia. Texto literário e contexto didático: os (des)caminhos na formação do leitor. Dissertação (Mestrado em Educação). Universidade Estadual de Campinas, Campinas, 1986.

CASTRO, Sandra Maria Penteado Ferreira. O Ensino de Leitura como reflexo de teorias linguísticas de leitura: uma crítica. Dissertação (Mestrado em Educação). Universidade Estadual de Campinas, Campinas, 1988.

PIETRI, Emerson de. A constituição do discurso da mudança no ensino de língua materna no Brasil. 2003. 202f. Tese (Doutorado em Linguística Aplicada) - Universidade Estadual de Campinas, Campinas, 2003.

SANT'ANA, Sueli. Proposta para o ensino de leitura $-1^{\circ}$ grau. Dissertação (Mestrado em Língua Portuguesa). Pontifícia Universidade Católica de São Paulo, São Paulo, 1988.

TAVARES, Cacilda. Ensino de leitura no $\mathbf{1}^{\mathbf{0}}$ grau: uma proposta sob o enfoque argumentativo. Dissertação (Mestrado em Língua Portuguesa). Pontifícia Universidade Católica de São Paulo, São Paulo, 1988.

RODRIGUES, José Luiz Pieroni. Formação do leitor: um projeto pedagógico para a sala de aula. Dissertação (Mestrado em Educação). Pontifícia Universidade Católica de São Paulo, São Paulo, 1989. 